\title{
Public Health Ethics in Covid-19 Scenario
}

\author{
Pranay Giripunje \\ MEDICAL INTERN, Department of Community Medicine, Jawaharlal Nehru Medical College, DattaMeghe \\ Institute of Medical Sciences, Wardha. \\ Email: pranaygiripunje@gmail.com
}

\begin{abstract}
Due to the pandemic, authorities of India followed public health measures to include its unfold within the India. a number of measures were imposed on public like obligatory home and institution quarantine, and social distancing. Although it being a public fitness emergency, the measures observed required crucial appraisal and use of an ethics and human rights technique. The goal of paper is to give an ethics and human rights standards to compare public fitness measures and use it to reflect on the ethical sides of these adopted through the authorities of India to consist of the unfold of pandemic.

first we discuss all the measure taken for ethics in the human rights concerns for public and their fitness measures with all the emergencies. We then brief India's social and economic conditions and some of the measures followed to include the unlock of pandemic. After that, some moral duty of some of India's responses to pandemic. We then do evaluation to discover the measures adopted by the authorities of India to slow the spread of pandemic, the ethics and human rights issues typically given for public health responder . we analysed that some of the measures violated ethics and human rights ideas. despite the fact that a some human rights can on occasion be legitimately lowered and constrained to meet public fitness dreams at some stage in public fitness emergencies, measures that infringe on human rights have to fulfil positive way of ethics and human rights standards. Other of the ones requirements i being powerful, strictly critical, proportionate to the value of the danger, questionable in the conditions, least restrictive. We tell about India's primary measures to fight the pandemic and tell that a variety of them fell incomplete of those criteria, and were not effective at all.
\end{abstract}

KEYWORDS: crucial appraisal ,India's responses, fulfil positive way of ethics, fell incomplete, unfold of pandemic

\section{INTRODUCTION}

\section{Effect In Pandemic On Fitness Care And Public Fitness}

The bioterrorism marketing campaign regarding anthrax, observed a large need to put together for public health emergencies, which include rising pathogens with ability to emerge as global pandemics. considerable highbrow and monetary capital changed into first of all invested in growing structures to comprise and mitigate those types of failures. but, what observed grow to be a absence of primary investment regardless of ailment transmission dangers inherent to a danger. one that has made pandemics not "likely" however "disaster". The fire like expansion of pandemic, the illness because of the pandemic, theindia within the first month of 2020 shows that no one were ready and geared up for any such pandemic and that hard choices will be vital inside the weeks and future months . some

of these choices include essential items removed from traditional care about govt involvement in a single's lifestyles.

inIndia, until march as mainly the majority of Indian dont live under a safe separate room, the problem was very huge and other side hospitals across getting ready for important care needs exceed their availability. Neither RT-PCR were available for active contamination nor serological tests available. We had lots of deaths due to pandemic. What has grow to be easy is that fitness departments and hospitals alike need to take into account how norms trade in a catastrophe. We provide this announcement as a way of highlighting a number of those traumatic conditions 


\section{When did Crises required to change in Norms}

ethics troubles require planning and reaction for public related health issue. under ordinary activities, the clinical part of ethics focused explaining at the desiredof needs of the person who is affected in general.

resourcesshould be provided to patients in based totally on requirement to sell affected man or woman well-being and admire affected person autonomy. In reality, of route, those norms generally have a tendency to manual cope with greater privileged patients. Many people loss of assets to pay for care from theiravailable money . as a consequence, even though belongings are sizable, fundamental ideas which encompass beneficence (selling particular) .

In the public fitness problem associated with considerable deficiency of equipment, fitness care should be provided to the person who is more of its need firstrather than discriminating .From a ethical side of view this is very profound way of practice during this pandemic. The government should pay for public health and wealth without discriminating to any citizen. They should had laida action plan earlier itself before the situation got worse.

This reaction to pandemic within the India has already located out some of ethical problem that will require interest. those encompass doubt about the imparting of freedom-restricting .which includes livein-domestic orders, the demanding situations of speakme successfully with the public and attractive organizations in selection making, using not proven restoration strategies, and allocating scarce assets.

\section{What all ethics and human rights are included in public health}

Moral thoughts like equality for all the people, not discriminating against anyone, giving everyone all the medication required for treating pandemic in free of cost, taking care of personal space.

Firstly the main issue is of preparedness of medical team and their proper time to time training. What India lack was proper coordination between different institution and self helpgroup. Though pandemic was first time but still proper preparedness and awareness to medical works could had solved the problem in great extent for the country.

The most important and debatable issue is the medicine given for treatment of pandemic as there is no clear study evidence of any usefulness of any medicine in this pandemic giving the medicine rationally to all the public is the top most priority in human ethics.

Drug chloroquine was and is still now given irrationally to all the patient suffering form this pandemic without any full proof evidence. Later it was proved that chloroquine was not very useful in treating this pandemic .[1]

Not only this but also chloroquine caused many systemic side effects in many of patients which was later turned to be much more fatal that the original pandemic itself - adverse drug reactions like abnormal heart rhythm, ventricular tachycardia, kidney failure, liver failure , hematuria, polyurea was a major side effect of chloroquine, hence question arise that was giving this drug was a good ethics or a bad ethics itself. This was kind of major violation of human rights as a common man would not know much about this. No one patient were explained about the side effect of these drug many healthy patient now have became unhealthy only because of this irrational use of drug and will continue surge of these patient post covid too.[2]

The next and second most important ethical aspect is that of availability of rapid testing due to which detection of cases were not possible hence normal population came in contact with this patient and this increase in cases has a huge surge. This 
has a different or another aspect too that those people who were not suffering from pandemic also could not come out of home and resume their work hence were forced to loose their job. So extending lockdown they would not die of pandemic but die because they have no job left to do so was extension of lockdown was also violation of ethical right or not is still a big question mark to all the people[3]

Third aspect is the mental and psychological stress that human face due to lockdown imposed by government for such a long time of which no person in country had experience.[4] Humans are social animal they need their surrounding people to live good mental life and on top of that due to unemployment and no payment form respected companies their mental health could be a major issue of concern, specially depression like states and suicidal tendency are common.

Could it had been possible to apply any alternative strategy to combat such problem .[5] country which imposed lockdown before Indian faced such problem already so it was possible us to learn from others mistakes and move forward for betterment of all the citizens living in the country

The quarantine period that was formulated by government was also not clear and changed time to time which created confusion among citizen, as the decision of quarantine was allotted to local govt authorities different authorities took their own decision in for quarantine not following a standard protocol. This resulted in spread of the pandemic more fast and more easily .for those who's quarantine period was for less day people in those places were happy with their authorities while the other people felt that their ethical rights were violated. Not completing quarantine for complete 14 days created a false negative cases which then acted like super carrier for the pandemic infecting entire family was it ethical to give right of the decision to local governing authorities, with aspect of hundreds of people who did their isolation properly but still got infected because of this false negative people.[6]

Unwanted use of antiviral drugs later was also increasing trend seen. No one had proof of its effectiveness or its usefulness but still without proper study and trials these drug were given to patients who did not even needed it .[7] drugs like flavipiravir and various steroids are still given as a primary modality of treatment which still is not proved by any crosssectional of cohort or any additional studies, though some studies show that these were very effective but were those study are not sufficient to prove that its uses are beneficial.[8]

High dose of antiviral are already proved for various systemic illness in our body may it be like hyper-uricemia and diarrhoea, also psychiatric depression among people and certain heart abnormalities such as arrhythmia, prolong QT syndrome, weight loss, loss of appetite this is also ethical issue for us as this can decrease quality and independent life of a well working and absolutely normal person.

Moreover all the study done is generally on the western population so its benefit to Asian is a big question, local inherit immunity plays a very important role in this pandemic

A specific community called as Sikhs wears turbans over their head so in some places they were exempted to wear mask was this ethical for rest of community. There are many alternative methods to wear a mask but no one were that concern to educate people.[9]

Most problem was faced by the pregnant mom no guidelines for pregnant ladies were given by government with was a big loop hole in handling this pandemic. Due to the fear of pandemic and no certain guidelines many of these pregnant ladies missed their dates of regular check up, many, missed their scan like dating scan or 
anomaly scan of ULTRA SOUND to be done.[10]

Many missed their meal due to lack of food availability in pandemic which affected their child health and their mental health too. Proper guidelines were needed to be implemented special plans to regularize their health check up should have been done.

\section{DISCUSSION:}

\section{Ethical Use For Resource Allocation}

Moral need to guide location of sources.. it may be latest settlement that to save lives through the population requires a stable desire, focus, maybe desires to get entry to scare fitness care assets in some unspecified time in the future of a public fitness disaster. however, the moral pursuit of that populace fitness intention is a complicated count.

Pandemic also needed that all the people living in country should get all the essential equipment and drugs on time and free of cost at correct time and at correct place with proper guidelines. But which assets should be given priority on the basis of triage is a very debatable in itself example, if we consider example of ventilators should be priority than vaccines these are arguable questions, because as responsibility to those people need to be balanced towards responsibilities we have triage on the basis of whomsoever is in need of it most should be given first. Age criterion itself has important role child age requires certain special attention towards their health (it should not be restricted only as characteristic but also the scientific prognostication of age should be considered) is a in addition arguable issue depend, one for which ethical consensus does not seem probable. wherein differing views among humans or cultures render the status quo of a community large in this trouble now not going, moral frameworks nice restrict "consideration of age to its prognostic role". This coheres with criminal guidance on the trouble as properly, despite the fact that there stays a few war of words in this point.

Ethical commitments need to additionally guide the techniques used to put in force allocation steering. "Bedside clinicians should not have obligation" for finding out whether or no longer their sufferers collect potentially lifesaving belongings; their fiduciary obligations to sufferers remain. putting in separate triage organizations honours these duties and allows deal with moral misery among medical personnel. Oversight of triage choice making ought to moreover be applied. A streamlined system of real-time assessment can assist make certain that errors and bias do now not electricity choices, notwithstanding the reality that during instances of critical shortage, even advanced evaluation procedures can also become impossible to govern. At a few level within the pandemic, retrospective evaluations of triage choice making will provide crucial facts to make certain that no companies are being disproportionately impacted in a manner that leads to systematic disadvantage.

These ethical issue does not only restrict for what was imposed on common people these also includes issue which doctors faced due to this pandemic .many citizen criticised and did not cooperate on medical community was this aspect of people not treating doctor in proper way is issue concerning for whole citizens

Another issue was for guidelines for patients who already had co morbidity like diabetes, hypertension, asthma had no specific treatment plan they were not treated separately which they needed to be. It was found that people who had comorbidity had more probability of morbidity and mortality in any given population .hence it is necessary to have a different plan of treatment for co-morbid patients.[11] 
Another aspect was treating patient with ayurvedic medicines which were not evidence based many people believed that this line of treatment would work and hence many positive patient didn't inform doctor though they had all the symptoms of the pandemic and these people spread this virus to hundreds of other peoples.

In this un-event-full situation too, some matters want to now not exchange. for example, patients have to be supplied the pleasant care feasible, such as palliation, intellectual health, and religious care helps. They maintain rights for the refusal remedy and obvious and passionate conversation approximately everyone care. On most of the people fitness level, a good deal of the focal point in a pandemic on implications of presidency proscribing liberty to shield population fitness. But, massive choices must automatically be made about allocating scarce assets as properly. nation health departments have to decide how to amazing distribute resources which includes PPE from kingdom and federal stockpiles, and who should get maintain of prioritized access to vaccine as quickly because it turns into to be had. In situations in which network distribution centers or public points of shelling out may be installation, public health must coordinate with other governmental entities to determine how, in which, and whilst the sort of internet site on line could be set up.[12]

There need to additionally be reputation of the locus of choice making for useful aid allocation, mainly, that neighbourhood fitness departments (LHDs) not often have the functionality to affirmatively pick who gets which sources-this is regularly dictated by using the usage of the dominion or federal government. at the same time, nearby health branch and Indian council of medical research are the "boots on the ground" and the sensible and clinical leaders in the ones crises[13-15]. Public fitness leaders have to have get right of entry to ethics assist to inform selection making, specially due to the fact no ethical framework can solve an extra edge over other on upward push inside this pretty complicated context of emergency reaction.

\section{Guarding for the justice}

one of the maximum morally troubling factors of public fitness crises is their disproportionate effect on businesses which might be socially disadvantaged. Indian economy had a major set back of its gross domestic product going to negative and performing worse day by day as the lockdown extended. We need to understand that socially backward people are at extra risk of contamination than rather privileged populations, given fitness disparities, lots much less able to protect themselves through preventive strategies at the side of social distancing, and additional confused thru public health reaction interventions that pose dangers to process protection or get right of entry to dietary assist applications[16-18]. boundaries to get proper of access to fitness care impede intervention at the same time as contributors of these organizations fall ill. "Structural inequalities underlie all of those factors". In every clinical and population-primarily based preference making, unique interest is owed to the ones companies, no longer as a form of reparation or remediation for societal injustice but in order to satisfy the center tenets of moral catastrophe response. exactly because of the reality those businesses will be hit hardest by way of using disaster, they need to be paid unique hobby. In clinical contexts, strategies need to be carried out to save you bias from affecting man or woman treatment alternatives and to ensure that method of not prioritization of those companies does no longer arise. In public fitness preference making, fitness and social issuer support should goal prone groups, maintaining in thoughts that get right of entry to transportation and employer- 
subsidized fitness care insurance can be restrained. Social facilitates which includes unwell pay, improved unemployment coverage, and protections against utilities shutoffs and evictions may also even help address inequities.[3]

Major setback was for citizen and it was ultimately citizens who has suffered a lot due to extension of lockdown. Young students who were in tenth standard twelve standard many undergoing medical and engineering exam were not allowed to give exam due to pandemic are in major depression about their future . they have big question mark of what to do next because they have wasted their year because of pandemic, was I possible to conduct all the exams online? This would at least compensate for some of the losses of what student faced due to pandemic not allowing student to appear in exam despite of social distance is violation of ethics from students[4]. Effect of pandemic in rural India is also important issue as they were not given proper attention to their demands cities are always preferred over villages in providing health care by all the government. Rural people are not even educated about the pandemic and its side effect hence these people require special attention[19-21].

Still there is a lot of scope for all of us to improve and learn from our past so that our betterment of our future .so that all the ethics are taken care of and each citizen get a better life to live which is his/her basic right as a citizen of this country.

\section{CONCLUSION}

even as moral norms shift in complicated crises inclusive of the pandemic, disaster reaction must be grounded on essential values that persist as society moves from recurring events to disaster. It is moral duty to re asses all the steps taken as we get more and more information about this pandemic not only asses but also re correct if any improper step that we took in past .proper follow up by regulating bodies is mandatory. The guidelines should be changed time to time as fast as possible. For both medical and public fitness contexts, disaster response need to be apparent with clean mechanisms of responsibility and should respond to desires respectfully, quite, efficiently, and effectively. "The stakes in this pandemic are profound, which magnifies the want to expand and implement a strong ethical framework for response and to talk that moral grounding to the general public". "most effective then will pandemic reaction be worth of bear in mind and sell the cohesion and mutual responsibility had to succeed".

\section{REFERENCES:}

[1] Cortegiani A, Ingoglia G, Ippolito M, Giarratano A, Einav S. A systematic review on the efficacy and safety of chloroquine for the treatment of COVID-19. J Crit Care. 2020 Mar 10.

[2] Devaux CA, Rolain J-M, Colson P, Raoult D. New insights on the antiviral effects of chloroquine against coronavirus: what to expect for COVID-19? Int J Antimicrob Agents. 2020 Mar 11:105938.

[3] Edwards E, Hillyard V. Man dies after taking chloroquine in an attempt to prevent coronavirus. NBCnews.com 2020 Mar 23 [cited 2020 Mar 29].

[4] Information for clinicians on therapeutic options for COVID-19 patients. Atlanta: Centers for Disease Control and Prevention; 2020 Mar 21 [cited 2020 Mar 29].

[5] Lexicomp, Lexi-Drugs Online, Chloroquine and Hydroxychloroquine - Adverse Reactions. Hudson, Ohio: Wolters Kluwer Clinical Drug Information, Inc; 2020; Updated 3/28/2020. Accessed 3/29/2020. 
[6] Liu J, Cao R, Xu M, et al. Hydroxychloroquine, a less toxic derivative of chloroquine, is effective in inhibiting SARS-CoV-2 infection in vitro. Cell Discov. 2020;6(1):16.

[7] Medical experts explain the use and potential adverse effects of chloroquine and hydroxychloroquine for COVID-19. Phoenix: American College of Clinical Toxicology; 2020 Mar 25 [cited 2020 Mar 27].

[8] Savarino A, Di Trani L, Donatelli I, Cauda R, Cassone A. New insights into the antiviral effects of chloroquine. Lancet Infect Dis. 2006 Feb;6(2):67-9.

[9] Organization. WH (2005) Statement on the second meeting of the International Health Regulations (2005) Emergency Committee regarding the outbreak of novel coronavirus (2019-nCoV)

[10] Kwon JY, Romero R, Mor G. New insights into the relationship between viral infection and pregnancy complications. Am J ReprodImmunol. 2014;71(5):387390. doi: 10.1111/aji.12243. [PMC free article] [PubMed] [CrossRef] [Google Scholar]

[11] Noufaily A, Enki DG, Farrington P, Garthwaite P, Andrews N, Charlett A. An Improved Algorithm for Outbreak Detection in Multiple Surveillance Systems. Statistics in Medicine 2012;32(7):1206-1222.

[12] Rue H, Martino S, Chopin N. Approximate Bayesian inference for latent Gaussian models using integrated nested Laplace approximations (with discussion). Journal of the Royal Statistical Society Series B 2009;71(2):319392.

[13] Wajpeyi, S.D.M. "Concept of Bioethics in Ayurveda." Journal of DattaMeghe Institute of Medical Sciences University 14, no. 6 (2019): S107-9. https://doi.org/10.4103/jdmimsu.jdmi msu_204_19.

[14] Anjankar, A., and P. Kute. "Bioethics in Laboratory Medicine." Journal of DattaMeghe Institute of Medical Sciences University 14, no. 6 (2019): S103-6. https://doi.org/10.4103/jdmimsu.jdmi msu_216_19.

[15] Nimbulkar, G., N. Dubey, S. Mandwar, S. Dharmapuria, A. Reche, and K.G. Chhabra. "Dental Practice Guidelines in the Precariousness of COVID-19: A Review." International Journal of Current Research and Review 12, no. 19 (2020): 82-87. https://doi.org/10.31782/IJCRR.2020 .12195 .

[16] Afaque, S.Y. "Association and Treatment of Diabetes in Patients Affected by COVID-19." International Journal of Research in Pharmaceutical Sciences 11, no. Special Issue 1 (2020): 1198-1201. https://doi.org/10.26452/ijrps.v11iSP L1.3591.

[17] Agrawal, A., P. Fulzele, K. Deo, Z.S. Quazi, and A. Daryapurkar. "Engineered Nano-in-Micro Drug Delivery Scheme against Sars-Cov2: A Hypothesis." European Journal of Molecular and Clinical Medicine 7, no. 7 (2020): 1892-1901.

[18] Agrawal, D., P. Jaiswal, and P. Bajaj. "Role of Dentist to Stop COVID-19: A Journey Map." International Journal of Research in Pharmaceutical Sciences 11, no. Special Issue 1 (2020): 880-84. https://doi.org/10.26452/ijrps.v11iSP L1.3109.

[19] Agrawal, D., P. Jaiswal, and B. Goyanka. "Diabetes and Covid-19: A Review." International Journal of Research in Pharmaceutical Sciences 11, no. Special Issue 1 (2020): 37679 . 
https://doi.org/10.26452/ijrps.v11iSP L1.2729.

[20] Agrawal, D., N. Khara, B. Mundada, N. Bhola, and R. Borle. "COVID-19 and Its Financial Effects on the Dental Fraternity and Health-Care Workers: A Literature Review." International Journal of Research in Pharmaceutical Sciences 11, no. Special Issue 1 (2020): 628-31. https://doi.org/10.26452/ijrps.v11iSP L1.2883.

[21] Andhare, R., S. Muley, and S. Bhirange. "Ayurvedic Perspective of COVID-19 Diagnosis and Management." Journal of Critical Reviews 7, no. 8 (2020): 1070-72. https://doi.org/10.31838/jcr.07.08.22 3. 